\title{
Propionibacterium acnes as a cause of shoulder osteoarthritis after three shoulder arthroscopies: a case report and review of preventive action
}

\author{
Batarabadja Bakriga $^{1}$, Emmanuel Beaudouin ${ }^{2}$, Noufanangue Kombate ${ }^{1}$, Gamal Ayouba ${ }^{1}$, \\ Yanick Dellanh $^{1}$, Atchi Walla ${ }^{1}$, Anani Abalo ${ }^{1}$, Assang Dossim ${ }^{1}$
}

${ }^{1}$ Department of Orthopaedic Surgery, CHU Sylvanus Olympio Lomé, Togo

${ }^{2}$ Department of Orthopaedic Surgery, Centre hospitalier de Chambéry, France

Received: 18 January 2017

Revised: 25 January 2017

Accepted: 10 February 2017

\section{*Correspondence:}

Dr. Batarabadja Bakriga,

E-mail: mbakriga@gmail.com

Copyright: (C) the author(s), publisher and licensee Medip Academy. This is an open-access article distributed under the terms of the Creative Commons Attribution Non-Commercial License, which permits unrestricted non-commercial use, distribution, and reproduction in any medium, provided the original work is properly cited.

\begin{abstract}
We report a case of postoperative osteoarthritis infection caused by $P$. acnes after shoulder arthroscopy, and review possible preventive action. A right-handed 24-year-old man presented an anterior instability of the left shoulder. The patient underwent an anterior stabilization by the latarjet procedure. Stabilization failed, requiring a second and third surgery. The patient returned 10 months later for suspected septic arthritis of his left shoulder. An arthroscopy lavage with bacteriological and anatomo-pathological sampling was carried out. The bacteriological results revealed a positive $P$. acnes culture. The patient was treated using antibiotherapy for 12 weeks with a combination of clindamicin and moxifloxacin. C-reactive protein (CRP) was negative two months after the onset of antibiotherapy. $P$. acnes is a anaerobic, non-sporulated, gram-positive bacillus. This commensal germ is part of the normal cutaneous flora and causes acne, but has also been recognized as a causative pathogen in osteoarticular infections since the 1990s, as described by Coden. Treatment is achieved via surgical debridement and intravenous antibiotics. We insist on preventive action in the form of a preoperative patient preparation protocol. Previous literature has underlined the important role of chlorhexidine or alcoholic iodinated polyvidone in the prevention of these infections. As $P$. acnes is a commensal germ of the patient's skin, prophylaxis should be reinforced by the thorough preparation of the surgery and surgical site. Clindamycin antibioprophylaxy specific to this germ should be administered for this surgery. To my knowledge, there is no specific antibioprophylaxy for shoulder surgery to date.
\end{abstract}

Keywords: Proprionibacterium acnes, Arthroscopy, Shoulder, Osteoarthritis, Togo

\section{INTRODUCTION}

Although Propionibacterium acnes (P. acnes) is commonly found on human skin, it is an uncommon pathogen in postoperative infections of the shoulder after arthroscopy. The clinical symptoms may resemble those observed after uneventful arthroscopic surgery, raising diagnostic challenges. ${ }^{1}$ The clinical presentation is usually insidious and nonspecific, yet a $P$. acnes infection could be an occult cause of postoperative shoulder pain. ${ }^{2}$ The presence of this organism can be overlooked because its discreet appearance may not seem worthy of diagnosis by culture or because, in contrast to many orthopaedic infections, multiple tissue samples and weeks of incubation are often necessary to recover this organism. ${ }^{3}$ We report a case of postoperative osteoarthritis infection caused by $P$. acnes after shoulder arthroscopy, and review possible preventive action.

\section{CASE REPORT}

A right-handed 24 year old man presented at the orthopaedic service for an anterior instability of the left shoulder. An injected arthroscanner revealed a lesion of 
the anterior inferior labrum and a Hill-Sachs/Malgaine lesion on the humeral slope as shown in Figure 1. The patient underwent an anterior stabilization of the left shoulder by anteglenoid stop in October 2009 as shown in Figure 2. After renewed instability caused by a fall, examination by arthroscanner revealed the failure of the abutment through pulling as given in Figure 3. A second arthroscopic stabilization was performed in June 2010, with reattachment of the labrum. The patient's condition had remained unstable, requiring a third procedure for iliac abutment as seen in Figure 4. The patient's condition remained stable during postoperative recovery, although he continued to experience pain, and the shoulder was stiff. The patient returned 10 months later for suspected septic arthritis of his left shoulder. No fever or discharge had been experienced since the previous operation. An arthroscopic lavage with bacteriological and anatomopathological sampling was carried out in November 2011. The bacteriological results revealed a positive culture with $P$. acnes (4 out of 6 deep samplings). The patient was treated using antibiotherapy for 12 weeks with a combination of clindamicin and moxifloxacin. C-reactive protein (CRP) was negative two months after the onset of antibiotherapy.

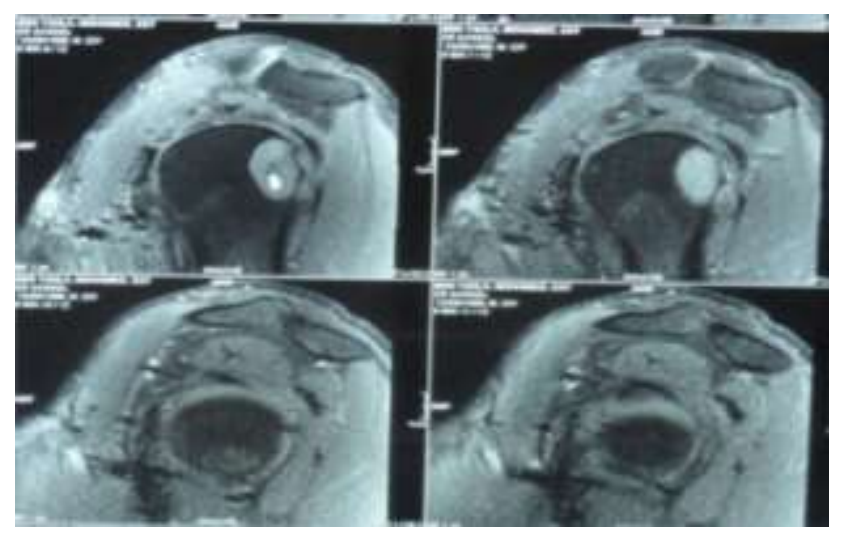

Figure 1: Arthroscanner showing bone and labral ligament lesions.

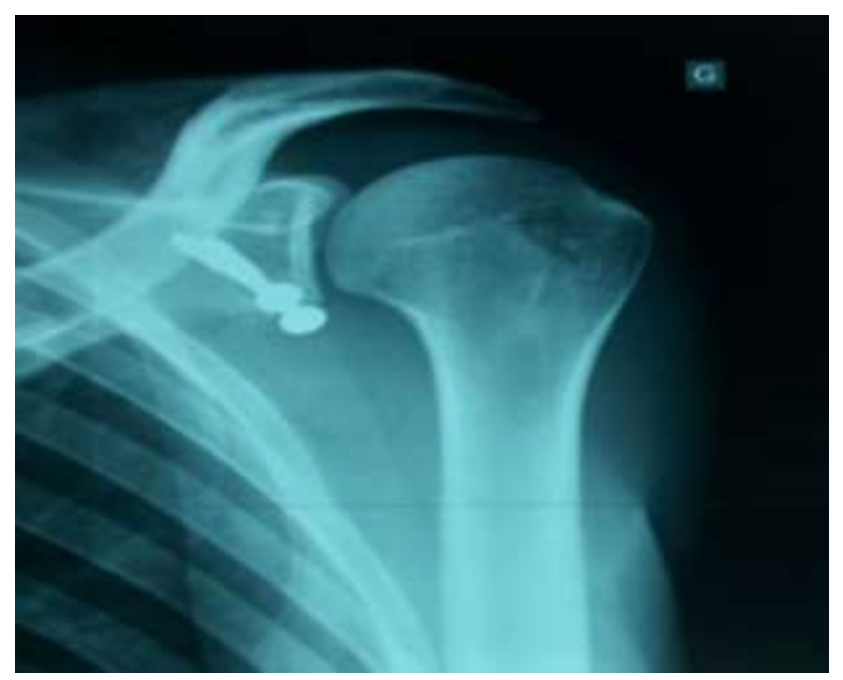

Figure 2: Anteglenoid stop.

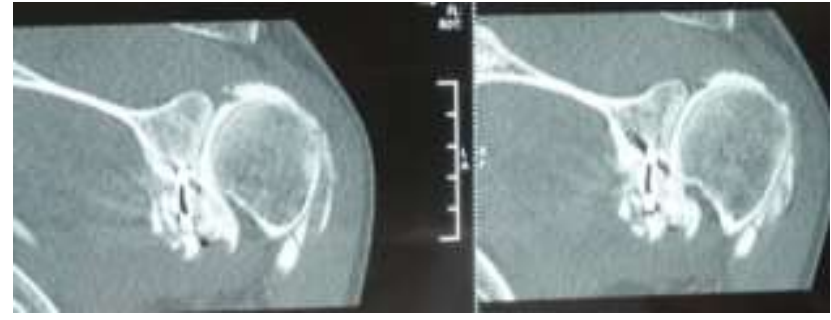

Figure 3: Arthroscanner after failure of the Latarjet procedure.

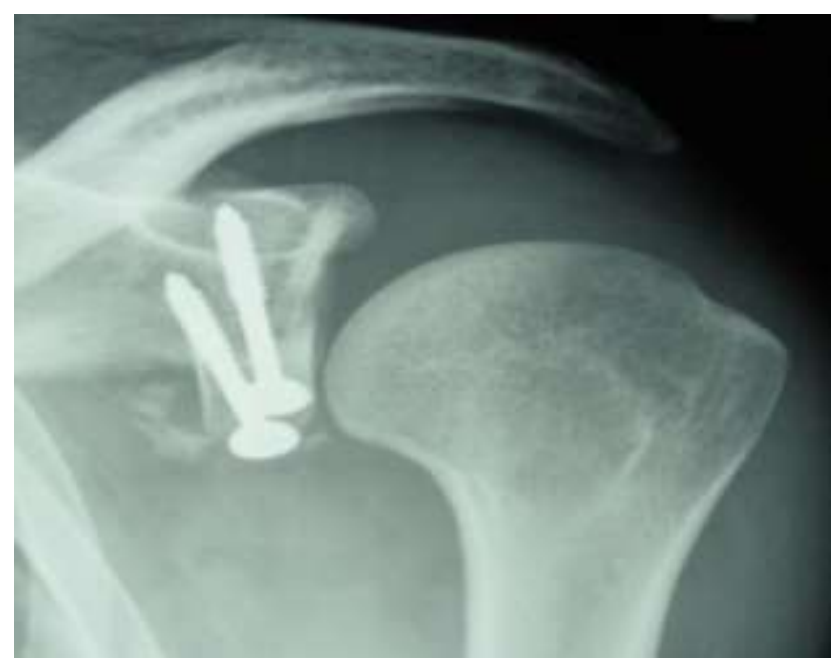

Figure 4: Iliac stop

\section{DISCUSSION}

The germ $P$. acnes is a anaerobic, non-sporulated, grampositive bacillus. This commensal germ is part of the normal cutaneous flora and causes acne. ${ }^{4,5}$ It is primarily known as a skin commensal. However, it can present as an opportunistic pathogen that causes invasive infections such as implant-associated infections via bacterial seeding. ${ }^{6} P$. acnes is primarily known as a contaminant, but has also been recognized as a causative pathogen in osteo-articular infections since the 1990s, as described by Coden. ${ }^{7}$ This germ is more commonly found on the upper limbs due to the proximity to the armpit and the pilosity of the thorax, particularly in males. As a result, it is found to be responsible for five times more infections in men than in women. ${ }^{8,9}$ The rate of skin colonization with $\mathrm{P}$. acnes is high at arthroscopic portals, especially in men. ${ }^{10}$ $P$. acnes is found to be the second germ responsible for infections of the prosthesis of the shoulder after staphylococcus aureus, and has been described in shoulder trauma, open rotator cuff repairs, shoulder instability surgery and shoulder arthroscopy. ${ }^{11-16}$

\section{Clinical and paraclinical signs}

The signs that should alert the surgeon are a discharge, wound dehiscence or a local erythema. In practice, the surgeon should note a shoulder that does not improve immediately or from 3 to 56 weeks after surgery. ${ }^{17}$ In our 
observation, the patient had not been well from the time of iliac abutment surgery, just after the second arthroscopic stabilization in June 2010, until the infection was diagnosed 4 months later. In the interval between performing arthroscopy and the diagnosis, the shoulder can become painful and unstable. This was the case of our patient. It is important that the diagnosis is made as soon as possible. Blood count, sedimentation rate and Creactive protein (CRP) are barely modified or unchanged. Bacterial cultures should be monitored for a minimum of 7-14 days when P. acnes is suspected to be the cause of infection through slow growth. Samples should be retained by the laboratory for three weeks in case of suspicion. $2,14,18,19$

\section{Treatment}

Treatment is achieved via surgical debridement and intravenous antibiotics. ${ }^{1}$ Debridement must be carried out early in the case of acute infection, and early diagnosis is essential. In the case of late diagnosis, debridement and the removal of material are performed at the same time in the case of late diagnosis, but can be carried out in two stages in the case of sepsis on arthroplasty. P. acnes is naturally resistant to Metronidazole but generally sensitive to penicillin and clindamycin. Intravenous antibiotic therapy should start rapidly, followed by $4-6$ weeks of oral treatment. Clindamycin may be used in prophylactic antibiotherapy. An osteo-articular infection always has a negative influence on the outcome of surgery. Functional abilities are often decreased following treatment.

\section{Prevention}

We insist on preventive action in the form of a preoperative patient preparation protocol. Previous literature has underlined the important role of chlorhexidine or alcoholic iodinated polyvidone in the prevention of these infections. ${ }^{20,21}$ Slow intravenous administration of antibioprophylaxis with cefazolin $2 \mathrm{~g}$, as recommended by the French Society of Anesthesia and Reanimation, has a low success rate for controlling $P$. acnes. $^{22}$ Despite standard skin preparation and prophylactic antibiotics, the rate of deep tissue inoculation with P. acnes in shoulder arthroscopy is much higher than the rate of infection reported in the literature. ${ }^{10,23}$ Some authors advocate the association of cefazolin and clindamycin, which is specific to P. acnes. The use of iodine-coated protective film (IOBAN®) is relatively efficient. ${ }^{24}$

\section{CONCLUSION}

As $P$. acnes is a commensal germ of the patient's skin, prophylaxis should be reinforced by the thorough preparation of the surgery and surgical site. Clindamycin antibioprophylaxy specific to this germ should be adminstered for this surgery. To my knowledge, there is no specific antibioprophylaxy for shoulder surgery to date. Early diagnosis and management are essential, with immediate treatment combining surgery and antibiotic therapy. Patient information and the training of personnel in quality care procedures should be used to reduce the risk of acute infection in shoulder surgery.

\section{Funding: No funding sources \\ Conflict of interest: None declared \\ Ethical approval: Not required}

\section{REFERENCES}

1. Bauer T, Boisrenoult P, Jenny JY. Post-arthroscopy septic arthritis: Current data and practical recommendations. Orthop Traumatol Surg Res OTSR. 2015;101(8):347-50.

2. Millett PJ, Yen Y-M, Price CS, Horan MP, Meijden OA van der, Elser F. Propionobacter acnes Infection as an Occult Cause of Postoperative Shoulder Pain: A Case Series. Clin Orthop Relat Res. 2011;469(10):2824-30.

3. Pottinger P, Butler-Wu S, Neradilek MB, Merritt A, Bertelsen A, Jette JL, et al. Prognostic Factors for Bacterial Cultures Positive for Propionibacterium acnes and Other Organisms in a Large Series of Revision Shoulder Arthroplasties Performed for Stiffness, Pain, or Loosening. J Bone Joint Surg Am. 2012;94(22):2075-83.

4. McGinley KJ, Webster GF, Leyden JJ. Regional variations of cutaneous propionibacteria. Appl Environ Microbiol. 1978;35(1):62-6.

5. Söderquist B, Holmberg A, Unemo $M$. Propionibacterium acnes as an etiological agent of arthroplastic and osteosynthetic infections-two cases with specific clinical presentation including formation of draining fistulae. Anaerobe. 2010;16(3):304-6.

6. Achermann Y, Vogt M, Leunig M, Wüst J, Trampuz A. Improved Diagnosis of Periprosthetic Joint Infection by Multiplex PCR of Sonication Fluid from Removed Implants. J Clin Microbiol. 2010;48(4):1208-14.

7. Coden DJ, Hornblass A. Propionibacterium acnes Orbital Abscess. Arch Ophthalmol. 1990;108(4):481 $-481$.

8. Patel A, Calfee RP, Plante M, Fischer SA, Green A. Propionibacterium acnes colonization of the human shoulder. J Shoulder Elbow Surg. 2009;18(6):897902.

9. Berthelot P, Carricajo A, Aubert G, Akhavan H, Gazielly D, Lucht F. Outbreak of postoperative shoulder arthritis due to Propionibacterium acnes infection in nondebilitated patients. Infect Control Hosp Epidemiol. 2006;27(9):987-90.

10. Chuang MJ, Jancosko JJ, Mendoza V, Nottage WM. The Incidence of Propionibacterium acnes in Shoulder Arthroscopy. Arthroscopy. 2015;31(9):1702-7. 
11. Singh JA, Sperling JW, Schleck C, Harmsen WS, Cofield RH. Periprosthetic infections after total shoulder arthroplasty: a 33-year perspective. J Shoulder Elbow Surg. 2012;21(11):1534-41.

12. Singh JA, Sperling JW, Schleck C, Harmsen W, Cofield RH. Peri-prosthetic Infections after Shoulder Hemiarthroplasty. J Shoulder Elbow Surg. 2012;21(10):1304-9.

13. Athwal GS, Sperling JW, Rispoli DM, Cofield RH. Acute deep infection after surgical fixation of proximal humeral fractures. J Shoulder Elbow Surg. 2007;16(4):408-12.

14. Herrera MF, Bauer G, Reynolds F, Wilk RM, Bigliani LU, Levine WN. Infection after mini-open rotator cuff repair. J Shoulder Elbow Surg. 2002;11(6):605-8.

15. Sperling JW, Cofield RH, Torchia ME, Hanssen AD. Infection after shoulder instability surgery. Clin Orthop. 2003;414:61-4.

16. Marecek GS, Saltzman MD. Complications in Shoulder Arthroscopy. Orthopedics. 2010;33(7):492 -7 .

17. Athwal GS, Sperling JW, Rispoli DM, Cofield RH. Deep infection after rotator cuff repair. J Shoulder Elbow Surg. 2007;16(3):306-11.

18. Haidar R, Najjar M, Boghossian AD, Tabbarah Z. Propionibacterium acnes causing delayed postoperative spine infection: Review. Scand J Infect Dis. 2010;42(6-7):405-11.

19. Dodson CC, Craig EV, Cordasco FA, Dines DM, Dines JS, Dicarlo E, et al. Propionibacterium acnes infection after shoulder arthroplasty: a diagnostic challenge. J Shoulder Elbow Surg. 2010;19(2):3037.
20. Sabetta JR, Rana VP, Vadasdi KB, Greene RT, Cunningham JG, Miller SR, et al. Efficacy of topical benzoyl peroxide on the reduction of Propionibacterium acnes during shoulder surgery. J Shoulder Elbow Surg. 2015;24(7):995-1004.

21. Murray MR, Saltzman MD, Gryzlo SM, Terry MA, Woodward CC, Nuber GW. Efficacy of preoperative home use of $2 \%$ chlorhexidine gluconate cloth before shoulder surgery. J Shoulder Elbow Surg. 2011;20(6):928-33.

22. Société française d'anesthésie et de réanimation. Antibioprophylaxie en chirurgie et médecine interventionnelle (patients adultes). Actualisation 2010. Ann Fr Anesth Réanimation. 2011;30(2):16890.

23. Levy O, Iyer S, Atoun E, Peter N, Hous N, Cash D, et al. Propionibacterium acnes: an underestimated etiology in the pathogenesis of osteoarthritis? J Shoulder Elbow Surg. 2013;22(4):505-11.

24. Falk-Brynhildsen K, Friberg Ö, Söderquist B, Nilsson UG. Bacterial Colonization of the Skin Following Aseptic Preoperative Preparation and Impact of the Use of Plastic Adhesive Drapes. Biol Res Nurs. 2012;15(2):242-8.

Cite this article as: Bakriga $B$, Beaudouin $E$, Kombate N, Ayouba G, Dellanh Y, Walla A, et al.

Propionibacterium acnes as a cause of shoulder osteoarthritis after three shoulder arthroscopies: a case report and review of preventive action. Int $\mathrm{J}$ Res Orthop 2017;3:314-7. 